\title{
AMPED LIFE
}

\section{Workethic.}

\section{BY JOHN COOPER HAMILTON}

$\mathrm{M}$ y transcranial magnetic stimulation cap clicks three times, but I feel nothing. The cap always does that when it's time for another pill. A recalibration? I'd ask, but no one would answer.

Sure enough, the medicate alarm sounds.

Before Mission Control gets on my case, I kick over to the medicine cabinet and pull the lever labelled "Carter", like a good rat. Grabbing the pill before it floats away, I pop it in my mouth.

Day 84 in orbit. Given our 12-off, 12-on regime, it's my 168th dose of CX-X, NASA's fourth-generation ampakine. It keeps me healthy and sane. More importantly, it keeps me working without an instant's sleep.

The cap clicks, buzzes, and someone taps my head. Quick, little taps, everywhere. My arm jerks, but I immediately feel more alert. Also: overworked and resentful.

The TMS cap is the second half of NASA's magic formula. Ampakines are arguably the first truly effective anti-sleep drug, but we've been chewing, sipping or shooting up to stay awake for thousands of years. The silly-looking silver cap conditions half my brain to sleep while other parts take over - as if I'm a dolphin, beached in orbit. It's novel, effective - and torture, if you ask me.

Nobody ever does.

"Carter, did you take your pill?"

People just give me orders. Giving them in the form of a question makes it worse.

"Carter here. I took the pill."

"The schedule shows a geological infrared survey is next. Are you there?"

I'd rather have $24 / 7$ cameras than questions.

"I'm on my way."

I do the survey, wondering what part of the button pushing couldn't be automated. I used to believe I was overpaid. Now I think they could never pay me enough, but most of my attention is on what's happening in my head. I'm entering my 'alternate' mind state.

Bursts of magnetism shut down certain neural pathways, encouraging the use of others, and shift the burden of being awake to different, presumably well-rested, paths.

ONATURE.COM Follow Futures: y @NatureFutures f go.nature.com/mtoodm
I'm alert, yeah. But there's more to it. I'm better.

Gibbon floats in. "Get your pill?"

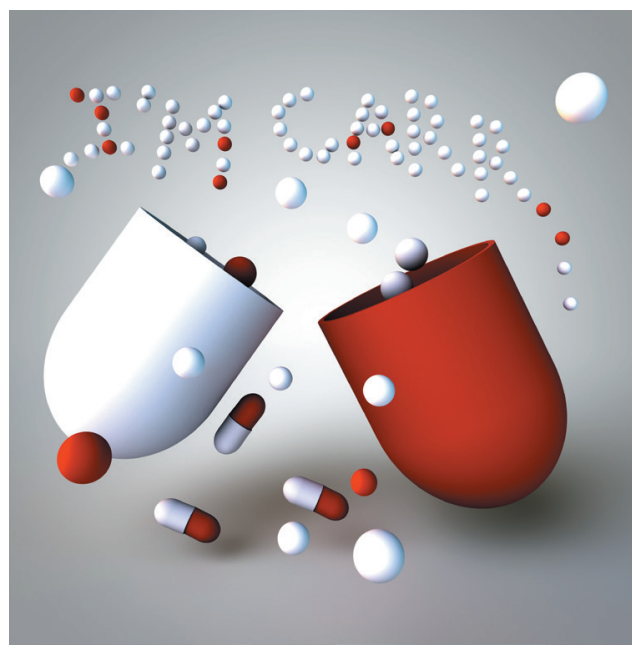

There are microphones, so I say: "Yes, sir." But I give him the finger.

Gibbon snarls silently and makes as if to punch me, but says: "Good." He does a backflip and sails into the station's other module.

"Carter, you're scheduled for a bathroom break. Are you there?"

"I'm on my way."

My cap clicks three times, the alarm goes off, I pull the lever, and take pill 264.

The cap does its thing. My toes tingle, momentarily numb, but I breathe easier.

Carter is so wound up. I'm not happy with the situation either, but I'm glad to give him a break.

Mission Control asks: "Carter, did you take your pill?"

I say: "Sure."

Gibbon's already in the module. We aren't talking much these days, but we glare. I have bloody fantasies about what I'd do to anyone who wasn't a psychological match, proven compatible by the latest $\mathrm{P} 300$-response personality tests. I grit my teeth. Bastards. The new tests are so much more reliable than the old tests, where you actually chose your answers.

Mission Control says: "Carter, you're scheduled for exercise. A high-intensity session. Are you there?"

"I'm on my way."

I exercise in the centrifuge, the cupola's observation window flashing past several times a second as I spin, too fast for me to be soothed by the sight of Earth. I think about the covers over my module's electronics, and how they might be bent and sharpened.

It's a long mission, with months to go.
They told us to always keep something in mind to look forward to.

Click-click-click, alarm, pill 368.

I take a deep breath as it goes down, anticipating day 184 . Almost halfway ... then back down to Earth. Maybe. Maybe we'll stay up here forever. Stiff, eyes frosting over, but free.

The cap clicks, lovingly tapping my skull, and euphoria washes over me. A leg jerks but it's a distant thing, floating to a different orbit.

Gibbon drifts in, staring.

Mission Control says: "Carter, did you take your pill?"

I'm not sure where Carter is. I'm Carr. I don't want to tell anybody, not with the others still to deal with.

I say: "Sure."

Gibbon nods and puts more of his strange marks on the wall by the hatchway. He uses one of the black grease-pencils Poge, the final crew member, makes from filter scrapings.

Gibbon and Poge had both become weird, and Carter was too numbed, too oppressed, to act. Not me. No brain-probes had ever picked me apart. I can do what I want. Anything.

"Carter, you're scheduled for a fungushybrid experiment. The info should be on your pad."

I run Heterobasidion irregulare through its paces while studying Gibbon's marks. Carter wouldn't have noticed the patterns. He's not smart enough. But I see the marks are characters. Twenty-six of them.

I read: "Call me Gibson."

My right hand does NASA's busywork while I pull out my own grease pencil with my left hand. I write, "I'm Carr."

I smile. I thought I was alone. I'm not.

Three men in a can 150 miles over the Earth are helpless -

My cap buzzes. It banishes fatigue, weariness and despair. I twitch, arms and legs, but welcome it - it makes me that much more pure.

Three men are helpless, but six are unstoppable when half are angels, iron will and bitter hate baked in by months of electromagnetic fire.

Oh, yes, I'm going home. A pinched conduit here, a lose wire there, and I'll be back early.

I have so much to look forward to.

John Cooper Hamilton writes humorous genre fiction, except when it's sombre or creepy. He even writes literary fiction if he thinks he can get away with it. 